The Effects of P-Atoms on the Selective Dehydrogenation of $\mathrm{C}_{6} \mathrm{H}_{10}$ over Model Ru Surfaces SiWei A. Chang, ${ }^{\dagger}$ Abinaya Sampath, ${ }^{\dagger}$ and David W. Flaherty*

\author{
Supporting Information
}

Department of Chemical and Biomolecular Engineering

University of Illinois at Urbana-Champaign, Urbana, IL 61801

*Corresponding author

Phone (217) 244-2816

e-mail dwflhrty@illinois.edu

${ }^{\dagger}$ Co-first authors 
Temperature Programmed Desorption (TPD) of $\mathrm{O}_{2}$ over $\mathrm{Ru}(0001)$ and $\mathrm{P}_{0.4}-\mathrm{Ru}(0001)$.

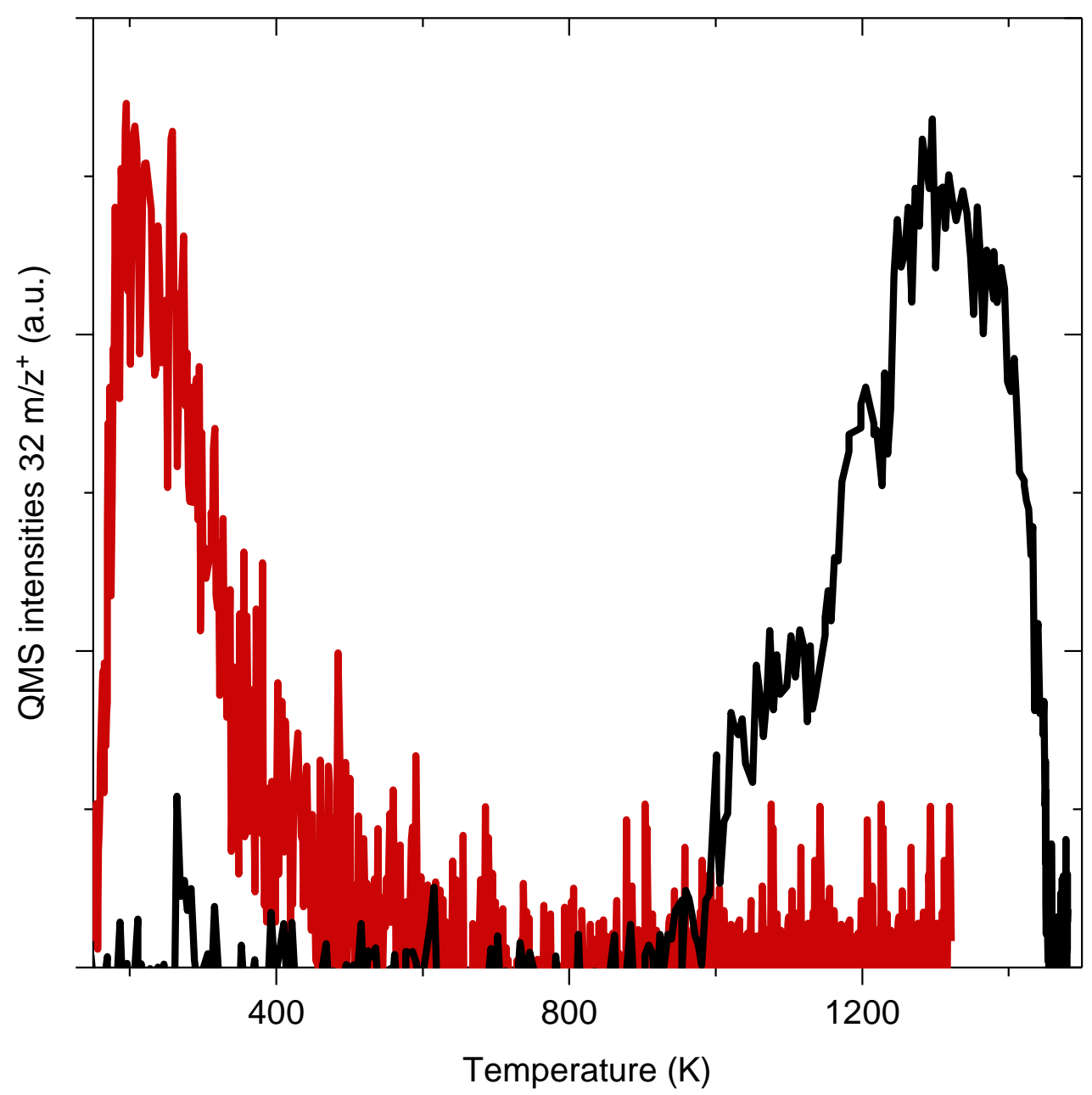

Figure S1. Desorption profile of $\mathrm{O}_{2}\left(32 \mathrm{~m} / \mathrm{z}^{+}\right)$from $\mathrm{TPD}$ of $\mathrm{O}_{2}$ over $\mathrm{Ru}(0001)$ (black) and $\mathrm{P}_{0.4-}$ $\mathrm{Ru}(0001)$ (red). $\mathrm{O}_{2}$ is adsorbed at $100 \mathrm{~K}$ for 15 seconds with a flux of $1.08 \times 10^{13}$ molecules cm$~^{-2}$ $\mathrm{s}^{-1}$ and is heated at $3 \mathrm{~K} \mathrm{~s}^{-1}$.

$\mathrm{O}_{2}$ adsorbed at $100 \mathrm{~K}$ on $\mathrm{Ru}(0001)$ and $\mathrm{P}_{0.4}-\mathrm{Ru}(0001)$ desorbs around $1296 \mathrm{~K}$ and $207 \mathrm{~K}$ on the two surfaces, respectively. This implies that there is negligible adsorbed $\mathrm{O}^{*}$ atoms for the formation of recombinative $\mathrm{CO}$ from the reaction between $\mathrm{O}^{*}$ and $\mathrm{C}^{*}$ on $\mathrm{P}_{0.4-\mathrm{Ru}} \mathrm{R}(0001)$ above 207 $\mathrm{K}$. However, the $\mathrm{O}_{2}$ begins to desorb from $\mathrm{Ru}(0001)$ around $990 \mathrm{~K}$, and there is likely recombination of $\mathrm{O}^{*}$ and $\mathrm{C}^{*}$ below that temperature on a coked $\mathrm{Ru}(0001)$ surface. 
Temperature Programmed Reaction (TPR) of $\mathrm{C}_{6} \mathrm{H}_{10}$ over Ru(0001).

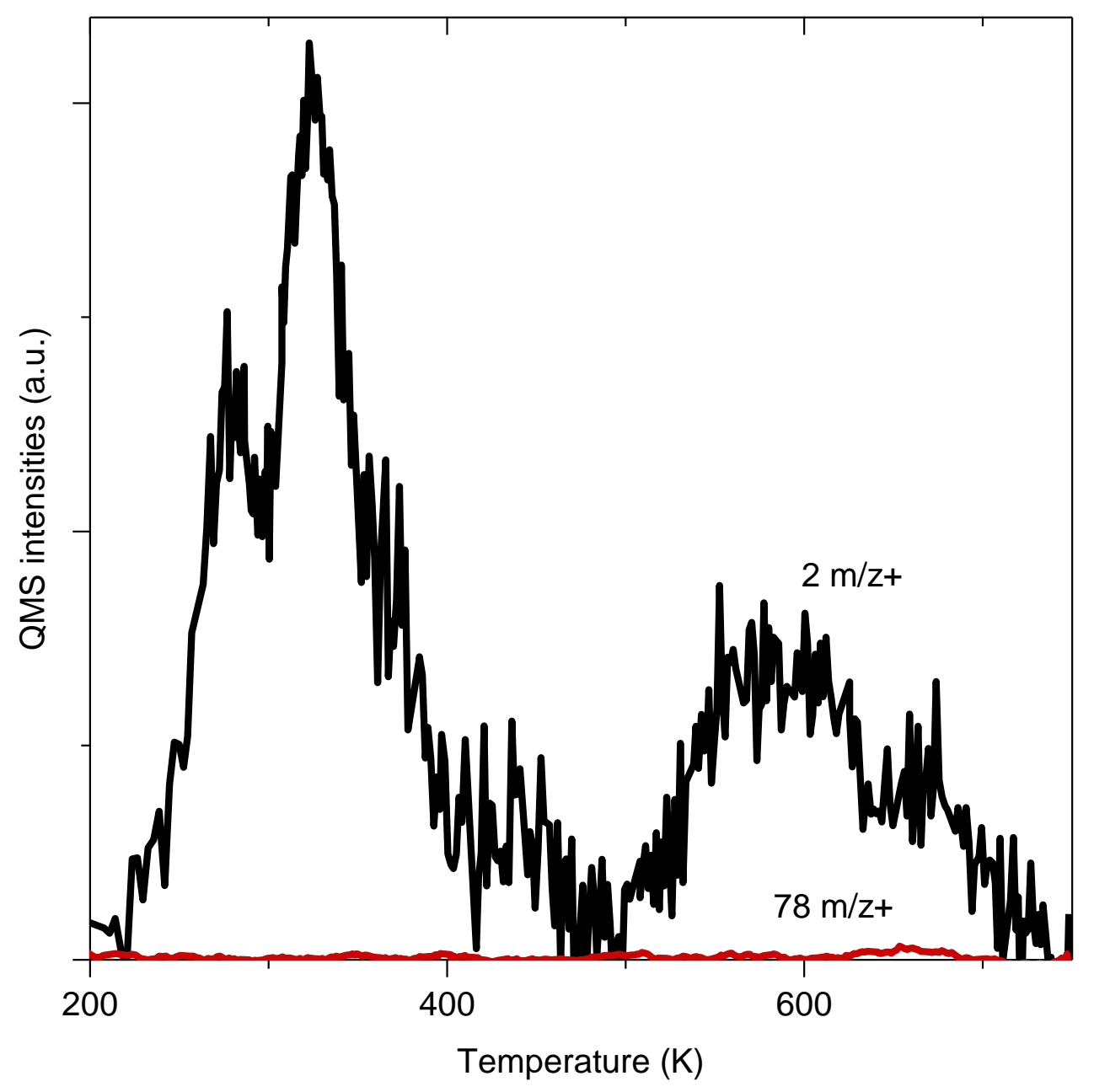

Figure S2. Desorption profiles of $\mathrm{H}_{2}\left(2 \mathrm{~m} / \mathrm{z}^{+}\right.$, black $)$and $\mathrm{C}_{6} \mathrm{H}_{6}\left(78 \mathrm{~m} / \mathrm{z}^{+}\right.$, red $)$from TPR of $\mathrm{C}_{6} \mathrm{H}_{10}$ over $\mathrm{Ru}(0001)$ adsorbed at $200 \mathrm{~K}$ at a surface coverage of $0.11 \mathrm{ML}$ and heated at $3 \mathrm{~K} \mathrm{~s}^{-1}$. Only $\mathrm{H}_{2}$ desorption was observed and not $\mathrm{C}_{6} \mathrm{H}_{6}$. 
Temperature Programmed Reaction of $\mathrm{C}_{6} \mathrm{H}_{6}$ over $\mathrm{Ru}(0001)$ and $\mathrm{P}_{0.4-\mathrm{Ru}}(0001)$.
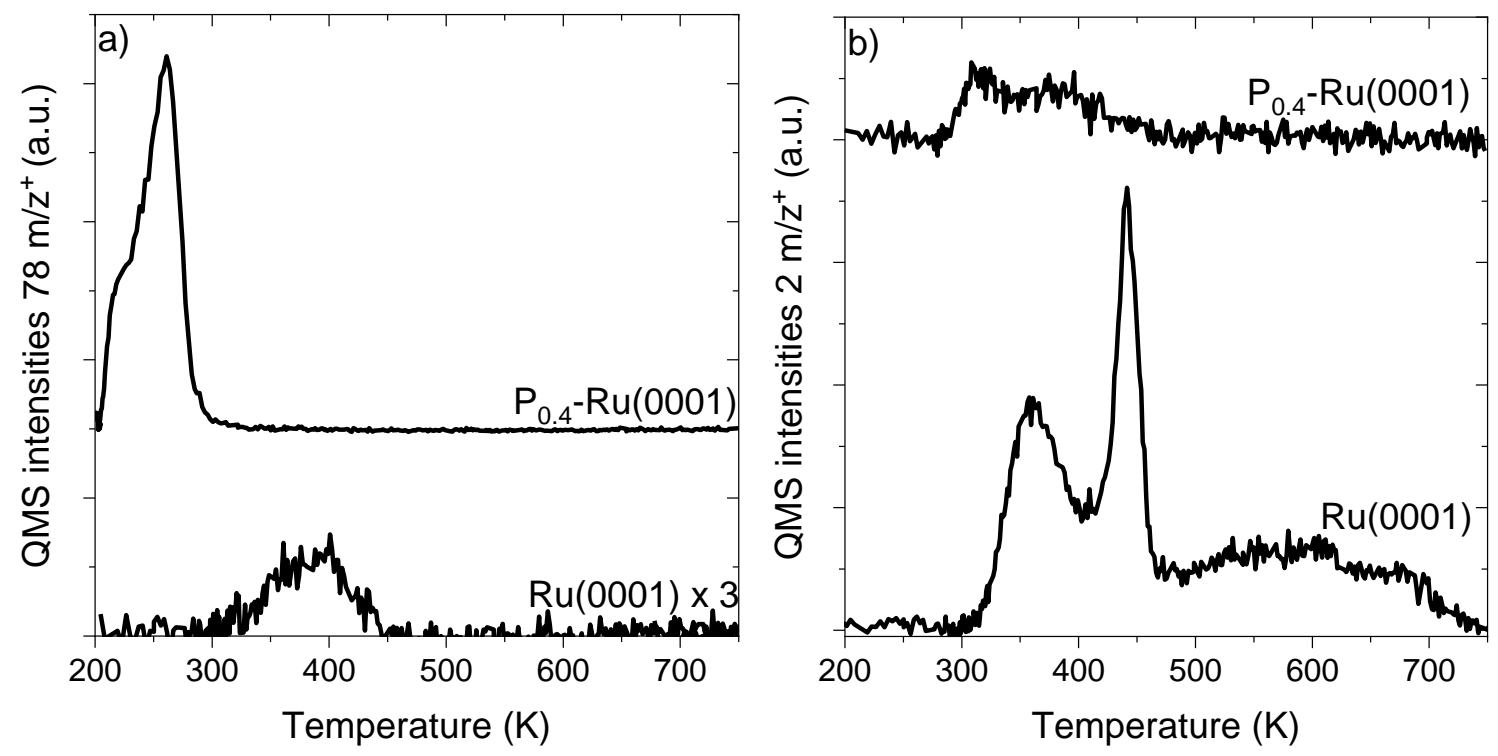

Figure S3. Desorption profiles of a) $\mathrm{C}_{6} \mathrm{H}_{6}\left(78 \mathrm{~m} / \mathrm{z}^{+}\right)$b) $\mathrm{H}_{2}\left(2 \mathrm{~m} / \mathrm{z}^{+}\right)$from TPR of $\mathrm{C}_{6} \mathrm{H}_{6}$ adsorbed at $200 \mathrm{~K}$ over $\mathrm{Ru}(0001)$ and $\mathrm{P}_{0.4}-\mathrm{Ru}(0001)$ and heated at $3 \mathrm{~K} \mathrm{~s}^{-1}$.

$\mathrm{C}_{6} \mathrm{H}_{6}$ adsorbed at $200 \mathrm{~K}$ on $\mathrm{Ru}(0001)$ and $\mathrm{P}_{0.4}-\mathrm{Ru}(0001)$ during TPR of $\mathrm{C}_{6} \mathrm{H}_{6}$ desorbed around 400 $\mathrm{K}$ and $260 \mathrm{~K}$ respectively. We observe that $\mathrm{P}$ atoms weaken the adsorption of $\mathrm{C}_{6} \mathrm{H}_{6}$ on $\mathrm{P}_{0.4-}$ $\mathrm{Ru}(0001)$ compared to $\mathrm{Ru}(0001)$ (by $\sim 37 \mathrm{~kJ} \mathrm{~mol}^{-1}$ using first order Redhead analysis and an assumed prefactor of $10^{13} \mathrm{~s}^{-1}$ ). We also observe that significant amount of $\mathrm{H}_{2}$ desorbs from $\mathrm{Ru}(0001)$ when compared to $\mathrm{P}_{0.4}-\mathrm{Ru}(0001)$ from $\mathrm{C}_{6} \mathrm{H}_{6}$ decomposition. This indicates that the $\mathrm{P}$ atoms weaken the $\mathrm{C}_{6} \mathrm{H}_{6}$ adsorption and facilitate desorption over decomposition over $\mathrm{Ru}(0001)$. 


\section{Derivation of $\mathrm{C}_{6} \mathrm{H}_{6}$ Formation Rate Expression under Pseudo Steady-State Conditions over $\mathrm{Ru}(0001)$ and $\mathrm{P}_{0.4}-\mathrm{Ru}(0001)$.}

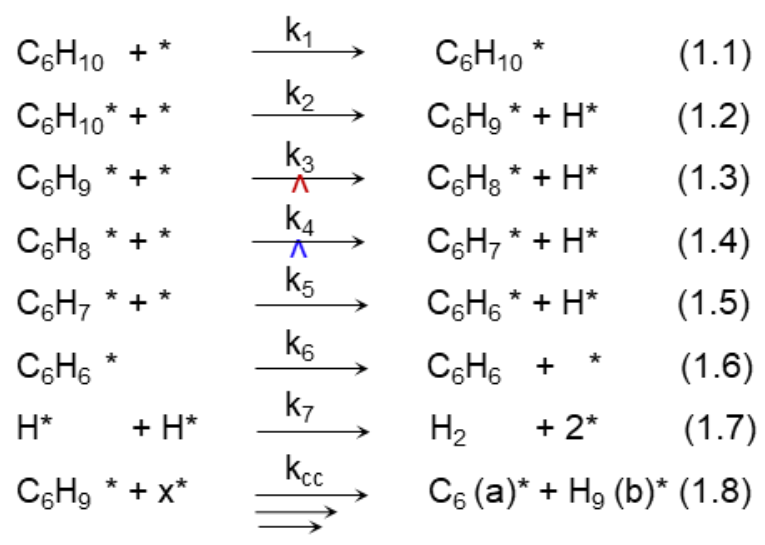

Scheme S1. Proposed mechanism for $\mathrm{C}_{6} \mathrm{H}_{10}$ dehydrogenation and decomposition on $\mathrm{Ru}(0001)$ and $\mathrm{P}_{0.4-\mathrm{Ru}}(0001)$. Here, $*$ denotes an empty site, $\mathrm{x}$, $\mathrm{a}$ and $\mathrm{b}$ represent integer number between 1 and 7 , with $\mathrm{a}+\mathrm{b}=\mathrm{x}$. $\mathrm{ky}$ is the rate constant for step 1 .y and $\mathrm{A} \longrightarrow$ indicates kinetically relevant step (blue on $\mathrm{Ru}(0001)$ and red on $\mathrm{P}_{0.4-\mathrm{Ru}}(0001)$ ). $\mathrm{k}_{\mathrm{cc}}$ represents the rate constant for the series of steps for complete decomposition of 2-cyclohexenyl.

Based on the TPR of $\mathrm{C}_{6} \mathrm{H}_{10}, 1,3$-cyclohexadiene, and 1,4-cyclohexadiene, and $\mathrm{C}_{6} \mathrm{H}_{10} \mathrm{RMBS}$, we propose a series of elementary steps for $\mathrm{C}_{6} \mathrm{H}_{10}$ dehydrogenation. Scheme $\mathbf{S 1}$ presents the elementary steps for $\mathrm{C}_{6} \mathrm{H}_{10}$ dehydrogenation (step 1.1 to 1.6) and $\mathrm{C}_{6} \mathrm{H}_{10}$ decomposition via series of $\mathrm{C}-\mathrm{C}$ and $\mathrm{C}-\mathrm{H}$ bond ruptures (step 1.8). The rate of formation of the surface intermediates $\mathrm{C}_{6} \mathrm{H}_{10} *$, 2-cyclohexenyl $\left(\mathrm{C}_{6} \mathrm{H}_{9} *\right)$, and $\mathrm{C}_{6} \mathrm{H}_{8} *$ are given by Equations S.1, S.2, and S.3, respectively, without accounting for the decomposition of $\mathrm{C}_{6} \mathrm{H}_{10}$. Here, [L] represents the total number of available sites and defined as the sum of $[*],[\mathrm{H*}],\left[\mathrm{C}_{6} \mathrm{H}_{6} *\right],\left[\mathrm{C}_{6} \mathrm{H}_{7} *\right],\left[\mathrm{C}_{6} \mathrm{H}_{8} *\right],\left[\mathrm{C}_{6} \mathrm{H}_{9} *\right]$, and $\left[\mathrm{C}_{6} \mathrm{H}_{10 *}\right]$. Here, $[x]$ represents the surface coverage of the intermediate $\mathrm{x}$.

$$
\begin{aligned}
& r_{C_{6} H_{10}^{*}}=k_{1}\left[C_{6} H_{10}\right][*]-\frac{k_{2}\left[C_{6} H_{10} *\right][*]}{[L]}-(S .1) \\
& r_{C_{6} H_{9}^{*}}=\frac{k_{2}\left[C_{6} H_{10} *\right][*]}{[L]}-\frac{k_{3}\left[C_{6} H_{9} *\right][*]}{[L]}-(S .2) \\
& r_{C_{6} H_{8}^{*}}=\frac{k_{3}\left[C_{6} H_{9} *\right][*]}{[L]}-\frac{k_{4}\left[C_{6} H_{8} *\right][*]}{[L]}-(S .3)
\end{aligned}
$$

$\mathrm{C}_{6} \mathrm{H}_{6}$ formed during TPR of $\mathrm{C}_{6} \mathrm{H}_{10}$ and 1,3-cyclohexadiene desorb around the same temperature implying step 1.4 to be the kinetically relevant step for $\mathrm{C}_{6} \mathrm{H}_{6}$ formation on $\mathrm{Ru}(0001)$. However, on $\mathrm{P}_{0.4}-\mathrm{Ru}(0001), \mathrm{C}_{6} \mathrm{H}_{6}$ production occurs at an earlier temperature from TPR of 1,3cyclohexadiene than $\mathrm{C}_{6} \mathrm{H}_{10}$, indicating $\mathrm{C}_{6} \mathrm{H}_{10} *$ (step 1.2) or 2-cyclohexenyl dehydrogenation (step 1.3) to be the kinetically relevant step for $\mathrm{C}_{6} \mathrm{H}_{6}$ formation from $\mathrm{C}_{6} \mathrm{H}_{10}$. Here we assume step $\mathbf{1 . 3}$ to be kinetically relevant on $\mathrm{P}_{0.4}-\mathrm{Ru}(0001)$. This gives us the rate expression for $\mathrm{C}_{6} \mathrm{H}_{6}$ formation

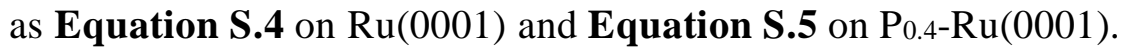




$$
\begin{array}{ll}
r_{C_{6} H_{6}}=\frac{k_{4}\left[C_{6} H_{8} *\right][*]}{[L]} & -(S .4) \\
r_{C_{6} H_{6}}=\frac{k_{3}\left[C_{6} H_{9} *\right][*]}{[L]} & -(S .5)
\end{array}
$$

The rate expressions for $\mathrm{C}_{6} \mathrm{H}_{6}$ formation at steady-state can be simplified by applying pseudo steady-state assumption (PSSA) on the intermediates $\mathrm{C}_{6} \mathrm{H}_{10} * \mathrm{C}_{6} \mathrm{H}_{9} *$, and $\mathrm{C}_{6} \mathrm{H}_{8} *$ on $\mathrm{Ru}(0001)$ and $\mathrm{C}_{6} \mathrm{H}_{10}$ and $\mathrm{C}_{6} \mathrm{H}_{9} *$ on $\mathrm{P}_{0.4}-\mathrm{Ru}(0001)$. The above mentioned can be mathematically written as Equation S.6 for $\mathrm{Ru}(0001)$ and Equation S.7 for $\mathrm{P}_{0.4-\mathrm{Ru}(0001) \text {. }}$

$$
\begin{array}{ll}
r_{C_{6} H_{10}^{*}}=r_{C_{6} H_{9} *}=r_{C_{6} H_{8} *}=0 & -(S .6) \\
r_{C_{6} H_{10} *}=r_{C_{6} H_{9} *}=0 & -(S .7)
\end{array}
$$

Simplifying Equations S.1, S.2, and S.3 using S.6 and S.7, we get Equations S.8 and S.9 valid on $\mathrm{Ru}(0001)$ and $\mathrm{P}_{0.4}-\mathrm{Ru}(0001)$, respectively.

$$
\begin{aligned}
& {\left[C_{6} H_{8} *\right]=\frac{k_{1}\left[C_{6} H_{10}\right][L]}{k_{4}}-(S .8)} \\
& {\left[C_{6} H_{9} *\right]=\frac{k_{1}\left[C_{6} H_{10}\right][L]}{k_{3}}-(S .9)}
\end{aligned}
$$

Based on the TPR of $\mathrm{C}_{6} \mathrm{H}_{10}$, at temperatures $>500 \mathrm{~K}$, all $\mathrm{C}_{6} \mathrm{H}_{6}$ and majority of the $\mathrm{H}_{2}$ desorb, leaving empty sites $(*)$ as the most abundant surface intermediate (MASI). Under these conditions (* as the MASI and > $500 \mathrm{~K}$ ), Equations S.4 and S.5 can be simplified using Equations $\mathbf{S . 8}$ and

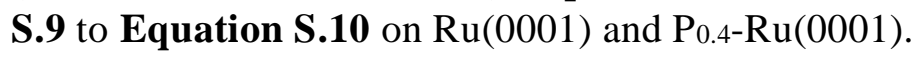

$$
\frac{r_{C_{6} H_{6}}}{[L]}=k_{1}\left[C_{6} H_{10}\right] \quad-(S .10)
$$

However, we should keep in mind that assuming any other step in Scheme S1 to be kinetically relevant, and applying PSSA on the dehydrogenated intermediates, we would obtain the same rate expression for $\mathrm{C}_{6} \mathrm{H}_{6}$ formation as long as $*$ is the MASI. 
Calculation of Apparent Coking Barrier from $\mathrm{C}_{6} \mathrm{H}_{6}$ Formation Rate during Reactive Molecular Scattering (RMBS) of $\mathrm{C}_{6} \mathrm{H}_{10}$ on $\mathrm{Ru}(0001)$ and $\mathrm{P}_{0.4}-\mathrm{Ru}(0001)$.

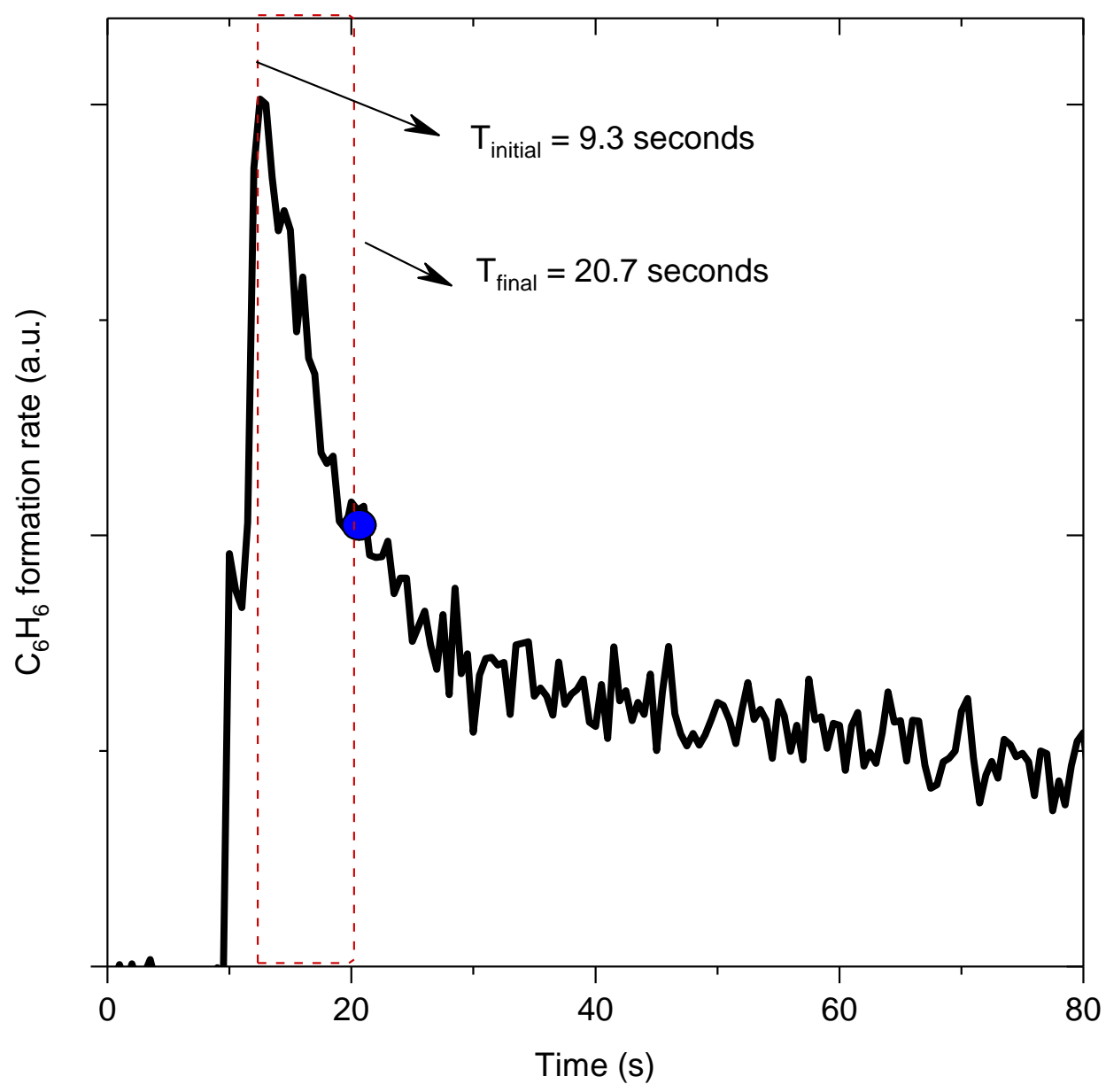

Figure S4. $\mathrm{C}_{6} \mathrm{H}_{6}$ production rate from $\mathrm{C}_{6} \mathrm{H}_{10} \mathrm{RMBS}$ on $\mathrm{Ru}(0001)$ at $600 \mathrm{~K}$, with a $\mathrm{C}_{6} \mathrm{H}_{10}$ flux of $1.08 \times 10^{13}$ molecules $\mathrm{cm}^{-2} \mathrm{~s}^{-1}$. The red lines indicate the initial time at maximum $\mathrm{C}_{6} \mathrm{H}_{6}$ formation rate and the final time at $50 \%$ of the initial $\mathrm{C}_{6} \mathrm{H}_{6}$ formation rate.

The decay in the rate of $\mathrm{C}_{6} \mathrm{H}_{6}$ formation during the RMBS of $\mathrm{C}_{6} \mathrm{H}_{10}$ is due to the coking of the catalyst surface. By calculating the inverse of time for the decay in the rate of $\mathrm{C}_{6} \mathrm{H}_{6}$ formation rate by half $\left(\tau_{1 / 2}\right)$ as a function of inverse temperature, we get the apparent coking barriers from RMBS of $\mathrm{C}_{6} \mathrm{H}_{10}$. 